\title{
25 Research Soure \\ Breeding and Characterization of The World's First Practical Rice Variety With Resistance to Brown Spot (Bipolaris Oryzae)
}

\section{Kengo Matsumoto}

Mie prefecture agricultural research institute

\section{Yuya Ota}

Mie prefecture agricultural research institure

\section{Tomohiro Yamakawa}

Mie prefecture agricultural research institute

\section{Teppei Ono}

Mie prefecture kuwana agricultural extension center

\section{Satomi Seta}

Mie prefecture agricultural research institute

\section{Yuto Honda}

Mie prefecture agricultural research institute

\section{Ritsuko Mizobuchi ( $\nabla$ ritsuko@affrc.go.jp )}

National Agriculture and Food Research Organization (NARO) https://orcid.org/0000-0001-8576-9350 Hiroyuki Sato

Ministry of Agriculture

\section{Original article}

Keywords: Oryza sativa L., Disease resistance, Brown spot, qBSfR11, bsr1, Marker-assisted selection, Near-isogenic line, Breeding variety

Posted Date: March 2nd, 2021

DOI: https://doi.org/10.21203/rs.3.rs-253417/v1

License: (c) (i) This work is licensed under a Creative Commons Attribution 4.0 International License. Read Full License 


\section{Abstract}

Background: Brown spot (BS) caused by Bipolaris oryzae is a serious disease of rice and decreases grain yield. Breeding for BS resistance is an economical solution but has not hitherto been achieved.

Results: To develop a practical BS-resistant variety, we introduced a chromosomal segment including a quantitative trait locus (QTL) for BS resistance, $q B S f R 11$, derived from the BS-resistant local resource 'Tadukan', into the genetic background of the high-yielding but susceptible 'Mienoyume'. Resistance is controlled by a single recessive gene in a 1.3-Mbp region. We named this gene bsr1 (brown spot resistance 1). The near-isogenic line bsr1-NIL had a greater yield with larger grain width than Mienoyume but similar other agronomic traits in fields where BS was mild; it had a significantly lower BS disease score and a $28.8 \%$ higher yield in fields where BS was more severe, and it showed resistance to multiple isolates of BS fungus. It showed stable resistance to BS and had excellent agricultural traits in the presence of BS.

Conclusions: We developed the bsr1-NIL with resistance to BS and applied it for variety registration to Ministry of Agriculture, Forestry and Fisheries in Japan as 'Mienoyume BSL'. It is the world's first practical breeding variety with resistance to BS.

\section{Background}

Brown spot (BS) is a fungal disease that is caused by Bipolaris oryzae and infects various parts of rice plants. The incidence of grain yield losses by BS and the use of countermeasures to BS (e.g., silicon fertilization) in the USA and India have been reported (Datnoff et al. 1991; Barnwal et al. 2013). The rate of yield reduction is up to $20 \%$ (Ou 1985; Chakrabarti 2001; Kamal and Mia 2009). It is highly possible that BS will become a more serious disease under global warming because its optimal temperature range for growth of the pathogen is relatively high (Mizobuchi et al. 2016).

In Japan in 2018, BS infected 197187 ha, the third-largest area after sheath blight (539 641 ha) and rice blast (296 518 ha) (JPPA 2019). The area peaked in 1984 (384 836 ha) and has since decreased, but it is gradually increasing again (JPPA 1975-2019). In Niigata prefecture, a decrease in the application of fungicides because of expansion of the use of rice-blast-resistant lines (Ishizaki et al. 2005) is presumed to be a reason for the spread of BS (Yamaguchi et al. 2007). As many rice-blast-resistant varieties have now been developed, we need to pay more attention to BS.

Some local genetic resources such as 'Tadukan' (Yoshii and Matsumoto 1951; Ohata and Kubo 1974), 'CH45' (Misra 1985), 'Dawn' (Eruotor 1986), and 'Tetep' (Yoshii and Matsumoto 1951; Ohata and Kubo 1974; Eruotor 1986) are resistant to BS, and some quantitative trait loci (QTLs) for resistance have been detected (Mizobuchi et al. 2016). We detected a major BS resistance QTL, qBSfR11, on chromosome (Chr.) 11 by field resistance tests with recombinant inbred lines derived from crosses between the resistant 'Tadukan' and the susceptible 'Hinohikari' (Sato et al. 2015). The Tadukan allele at the QTL also conferred BS resistance in the 'Koshihikari' background (Sato et al. 2015). Two other QTLs were detected 
near qBSfR11: BSq11.2v, derived from IR62266 (Katara et al. 2010), and qBSR11-kc, from 'CH45' (Matsumoto et al. 2017b). However, very few QTLs or genes for resistance to BS have been reported, and there are no reports of the development of BS-resistant varieties by using resistance QTLs.

The aim of this study was to develop a practical variety with resistance to BS. In Mie prefecture, the highyielding japonica variety 'Mienoyume' is grown on about 800 ha of paddy fields. It has resistance to rice blast owing to the presence of the resistance gene Pita-2, but not to BS (Yamakawa et al. 2002). In our previous study, Mienoyume was one of the varieties most susceptible to BS of about 140 accessions including NIAS core collections of Japanese rice landraces and world rice (Matsumoto et al. 2017a). Because Mienoyume has high yield and good grain appearance, we developed near-isogenic lines (NILs) of it with BS resistance. We bred 'Mienoyume BSL', which is the world's first practical variety with resistance to BS. We discuss the stability of resistance to multiple BS strains.

\section{Materials And Methods}

\section{Breeding of NILs}

Figure 1 shows the breeding scheme used for the development of the NILs. The donor parent (R307-48-9) was a NIL developed by Sato et al. (2015), in which the major resistance QTL (qBSfR11) on Chr. 11, derived from indica 'Tadukan' (resistant), had been introduced into the genetic background of 'Koshihikari' (susceptible). qBSfR11 was transferred into the Mienoyume background by sequential backcrossing method. During backcrossing or selfing from 2014 to 2015, promising individuals or lines were selected by marker-assisted selection with simple sequence repeat (SSR) markers (McCouch et al. 2002) based on the target region on Chr. 11. In 2016, six SSR markers at the qBSfR11 locus were used to verify the size of the substituted segments. In 2017, we evaluated the BS resistance of $52 \mathrm{NILs}\left(19 \mathrm{BC}_{5} \mathrm{~F}_{3}, 33 \mathrm{BC}_{4} \mathrm{~F}_{4}\right)$, divided into 12 groups based on their generations and genotypes, by field evaluation testing described later (Fig. 2a). The whole genome of six resistant NILs (one in group-9, two in group-10, three in group-11) was surveyed by using 243 single-nucleotide polymorphism (SNP) markers distributed evenly across the 12 chromosomes (Nagasaki et al. 2010; Additional file 1: Table S1). A BS-resistant NIL, named bsr1-NIL, was selected as a promising line. In 2018, three more SSR markers (RM27159, RM27163, and RM27244), located downstream of the six SSR markers used in 2016, were used to determine the genotype of bsr1NIL in the qBSfR11 region and to delimit the chromosomal location of the BS-resistance gene in a group11 NIL with the shortest Tadukan segment among the BS-resistant lines.

\section{Field trials}

Field trials were conducted in the paddy fields at Mie Prefecture Agricultural Research Institute (Mie, Japan) in Matsusaka $\left(34^{\circ} 63^{\prime} \mathrm{N}, 136^{\circ} 48^{\prime} \mathrm{E}\right)$ and Iga $\left(34^{\circ} 70^{\prime} \mathrm{N}, 136^{\circ} 13^{\prime} \mathrm{E}\right)$.

BS resistance was evaluated in Iga on a scale of 0 (no incidence) to 9 (severe) according to the procedure of Matsumoto et al. (2016) by using B. oryzae strain Iga-2 (Acc. No. 245177, MAFF Genebank) with two or three replications. In 2016, the inheritance mode of BS resistance was evaluated by using 153 
individuals in the $\mathrm{BC}_{4} \mathrm{~F}_{2}$ generation derived from one $\mathrm{BC}_{4} \mathrm{~F}_{1}$ individual that had been confirmed to be heterozygous at the $q B S f R 11$ locus by using SSR marker RM27073 (McCouch et al. 2002). We investigated their RM27073 genotype and BS resistance by field evaluation testing.

Other tests of agronomic traits of bsr1-NIL were conducted in Iga and Matsusaka, with two replications in 2018 and three replications in 2019 and 2020. bsr1-NIL and Mienoyume were transplanted on 14 or 15 May in Matsusaka and on 10 or 11 May in Iga at four seedlings per hill in 120 hills and six rows per replication, with a spacing of $30 \mathrm{~cm} \times 15 \mathrm{~cm}$ in 2018 and 2019 and $30 \mathrm{~cm} \times 18 \mathrm{~cm}$ in 2020. Nitrogen fertilizer was applied at $4.8 \mathrm{~g} \mathrm{~N} \mathrm{~m}^{-2}$ at transplanting and $4.0 \mathrm{~g} \mathrm{~m}^{-2}$ at heading in Matsusaka, and at 5.6 and $3.4 \mathrm{~g} \mathrm{~m}^{-2}$, respectively, in Iga. Major agronomic traits (days to heading, culm length, panicle length, brown rice yield, panicle number, 1000-grain weight, brown rice protein content, grain appearance, grain shape) were measured each year. Days to heading was calculated as days from transplanting to heading. From the results of these trials, bsr1-NIL was confirmed as a candidate for a practical BS-resistant variety for its high yield.

In 2020, to evaluate the effect of $q B S f R 11$ on agronomic traits, we grew bsr1-NIL and Mienoyume in a part of the test field where BS was more severe after heading. Seedlings were transplanted on 28 May at four seedlings per hill in 80 hills and four rows per replication (three replications), with a spacing of $30 \mathrm{~cm}$ $\times 15 \mathrm{~cm}$. Slow-release $\mathrm{N}$ fertilizer was applied at $7.5 \mathrm{~g} \mathrm{~N} \mathrm{~m}^{-2}$ at transplanting. Spreader plants (Mienoyume inoculated with Iga-2 strain) were planted around the plots but not within them. Plant height, stem number, and leaf greenness (SPAD value) were measured as indicators of crop growth at the panicle formation stage, when BS had not yet occurred. SPAD values were measured with a SPAD-502Plus chlorophyll meter (Konika Minolta, Inc., Tokyo, Japan). Yield, yield components (panicle number, spikelet number per panicle, percentage of filled spikelets, and 1000-grain weight), brown rice protein content, and grain appearance were measured at maturity.

\section{Inoculation test using multiple BS strains}

In 2020, bsr1-NIL, Mienoyume (susceptible), and Tadukan (resistant) were grown in $5.5 \mathrm{~cm} \times 15.0 \mathrm{~cm} \times$ $9.5 \mathrm{~cm}$ containers filled with sterilized soil (Clean No. 2, Ibiko Corporation, Gifu, Japan) inside a greenhouse of Mie Prefecture Agricultural Research Institute. Five seeds of each were sown in a row, at four rows per container. The isolates of BS fungus used were B. oryzae T. AOKI AR0126 (isolated in Okinawa prefecture; MAFF Genebank Acc. No. 235499) and F-1 (isolated in Ehime prefecture; Acc. No. 305067). Inoculation of fungus and evaluation of disease symptoms followed the methods of Sato et al. (2008).

\section{DNA isolation and marker analyses}

Total DNA was extracted from the leaves by using the CTAB method (Murray and Thompson 1980). PCR and electrophoresis for SSR analyses followed the method of Sato et al. (2015), but with Taq enzyme 
from GoTaq Green Master Mix (Promega, Madison, WI, USA), $55^{\circ} \mathrm{C}$ annealing temperature, and $3.0 \%$ gel concentration. All experimental procedures for the SNP analysis followed the method of Sato et al. (2015).

\section{Result}

\section{Graphical representation of NIL genotypes}

Figure 2a shows the graphical genotypes at the qBSfR11 region (between RM1219 and RM2191-1) and the phenotypes (BS disease scores and heading dates) of $52 \mathrm{NILs}\left(\mathrm{BC}_{5} \mathrm{~F}_{3} 19\right.$ lines, $\mathrm{BC}_{4} \mathrm{~F}_{4} 33$ lines) that had been confirmed to be homozygous for either the Tadukan allele or the Mienoyume allele between RM1219 and RM2191-1 by SSR analysis in 2016. The genotype of the donor parent (R307-48-9) was the same as that of Tadukan ( $q B S f R 11$ donor), and its BS disease score was significantly lower than that of Mienoyume. In both the $\mathrm{BC}_{5} \mathrm{~F}_{3}$ generation and the $\mathrm{BC}_{4} \mathrm{~F}_{4}$ generation, the groups with Mienoyume segments from RM27073 to RM2191-1 (groups-1, 2, 3, 5, 6, 7, and 8) had the same disease scores as Mienoyume. In contrast, the groups with Tadukan segments there (groups-4, 9, 10, 11, and 12) had lower disease scores than Mienoyume. The heading dates of all 52 NILs were the same as that of Mienoyume. SSR analysis downstream of RM2191-1 in 2018 showed that a NIL of group-11 had a 1.3-Mbp Tadukan segment from RM27073 to RM27159 (Fig. 2b).

\section{Inheritance mode of BS resistance}

Figure 3 shows the frequency distribution of $\mathrm{BS}$ disease scores in $153 \mathrm{BC}_{4} \mathrm{~F}_{2}$ individuals, based on the genotypes of SSR marker RM27073 at the qBSfR11 locus. Disease scores of 0 to 4 were considered to indicate resistance and those of 4.5 to 9 to indicate susceptibility. The $\mathrm{BC}_{4} \mathrm{~F}_{2}$ individuals segregated in a 1:3 ratio of resistant: susceptible (Table 1 ), confirming that the resistance to $B S$ is controlled by a single recessive gene at the qBSfR11 locus. We named this gene bsr1 (brown spot resistance 1).

\begin{tabular}{|c|c|c|c|c|}
\hline \multirow[t]{2}{*}{ Generation } & \multicolumn{2}{|c|}{ Number of individuals } & \multirow{2}{*}{$\begin{array}{l}x^{2} \text {-value } \\
(1: 3)\end{array}$} & \multirow[t]{2}{*}{$p$-value } \\
\hline & Resistant type & Susceptible type & & \\
\hline $\mathrm{BC}_{4} \mathrm{~F}_{2}$ & 36 & 117 & 0.18 & 0.67 \\
\hline
\end{tabular}

\section{Genetic backgrounds and agronomic traits of bsr1-NIL}

We selected a resistant NIL ( $b s r 1-\mathrm{NIL}$ ) in the $\mathrm{BC}_{4} \mathrm{~F}_{4}$ generation in 2017. bsr1-NIL had the group-9 genotype (Fig. 2a). It had R307-48-9 segments on Chr. 11 (3.5 Mbp from aa 11004652 to aa 11007953; Fig. 4c). On all other chromosomes except for Chr. 11, it was homozygous for Mienoyume segments. The other five 
lines tested for the whole-genome survey had R307-48-9 segments on all other chromosomes except for Chr. 11.

In both yield-trial paddy fields where BS was less severe than in the BS resistance test field, there was no significant difference in BS disease score between bsr1-NIL and Mienoyume (Table 2). However, some traits were significantly different. In Matsusaka, brown rice yield and grain width of bsr1-NIL were $34 \mathrm{~g}$ $\mathrm{m}^{-2}$ higher and $0.06 \mathrm{~mm}$ larger, respectively, than those of Mienoyume. In Iga, grain width of bsr7-NIL was $0.06 \mathrm{~mm}$ larger than that of Mienoyume. In a part of the BS resistance test field where BS was more severe, the BS disease score of bsr1-NIL was 3.0 lower than that of Mienoyume (Table 3; Fig. 4a, b). There were no significant differences in growth characteristics at the panicle formation stage between bsr1-NIL and Mienoyume. On the other hand, brown rice yield and percentage of filled spikelets of bsr1-NIL were respectively $106 \mathrm{~g} \mathrm{~m}^{-2}$ and $12.3 \%$ higher than those of Mienoyume. In addition, 1000-grain weight of $b s r 1-\mathrm{NIL}$ was $0.4 \mathrm{~g}$ larger than that of Mienoyume (n.s., $p=0.06$ ). These results suggest that $\mathrm{BS}$ reduced the ripening of rice and decreased the brown rice yield. The protein content of brown rice of bsr1-NIL was $1.3 \%$ lower than that of Mienoyume.

Table 2 Agronomic traits of bsr 1 -NIL and Mienoyume in 3 years (2018-2020)

\begin{tabular}{|c|c|c|c|c|c|c|c|c|c|c|c|c|c|}
\hline \multirow{3}{*}{ Test site } & \multirow{3}{*}{$\begin{array}{l}\text { Line or } \\
\text { variety }\end{array}$} & \multirow[b]{2}{*}{$\begin{array}{c}\text { BS } \\
\text { disease } \\
\text { score }\end{array}$} & \multirow[b]{2}{*}{$\begin{array}{l}\text { Days to } \\
\text { heading }\end{array}$} & \multirow[b]{2}{*}{$\begin{array}{l}\text { Culm } \\
\text { length }\end{array}$} & \multirow[b]{2}{*}{$\begin{array}{l}\text { Parnicle } \\
\text { length }\end{array}$} & \multirow[b]{2}{*}{$\begin{array}{c}\text { Brown rice } \\
\text { yield }\end{array}$} & \multirow[b]{2}{*}{$\begin{array}{l}\text { Panicle } \\
\text { number }\end{array}$} & \multirow[b]{2}{*}{$\begin{array}{c}1000 \text {-grain } \\
\text { weight }\end{array}$} & \multirow[b]{2}{*}{$\begin{array}{c}\text { Protein } \\
\text { content of } \\
\text { brown rice }\end{array}$} & \multirow[b]{2}{*}{$\begin{array}{c}\text { Grain } \\
\text { appearance }\end{array}$} & \multicolumn{3}{|c|}{ Grain shape } \\
\hline & & & & & & & & & & & $\begin{array}{l}\text { Grain } \\
\text { length }\end{array}$ & $\begin{array}{l}\text { Grain } \\
\text { width }\end{array}$ & $\begin{array}{c}\text { Grain } \\
\text { length to } \\
\text { widthratio }\end{array}$ \\
\hline & & $(0-5)$ & (days) & $(\mathrm{cm})$ & $(\mathrm{cm})$ & $\left(\mathrm{g} \mathrm{m}^{-2}\right)$ & $\left(\mathrm{m}^{-2}\right)$ & (g) & $(\%)$ & $(\%)$ & $(\mathrm{mm})$ & $(\mathrm{mm})$ & \\
\hline \multirow[t]{3}{*}{ Matsusaka } & bsr1-NIL & $0.0 \pm 0.1$ & $79.7 \pm 1.2$ & $72.1 \pm 5.4$ & $20.8 \pm 0.5$ & $639 \pm 12$ & $400.6=47.2$ & $23.0 \pm 0.8$ & $7.0=0.5$ & $76.1 \pm 14.4$ & $5.07 \pm 0.04$ & $2.75 \pm 0.03$ & $1.85 \pm 0.01$ \\
\hline & Mienoyume & $0.8 \pm 1.1$ & $79.7 \pm 1.2$ & $73.4 \pm 6.2$ & $20.8 \pm 0.5$ & $605 \pm 14$ & $388.4 \pm 39.3$ & $22.5 \pm 0.8$ & $7.2 \pm 0.6$ & $77.8 \pm 10.6$ & $5.08 \pm 0.18$ & $2.69 \pm 0.02$ & $1.89 \pm 0.07$ \\
\hline & $t$-test & & & & & $*$ & & & & & & $*$ & \\
\hline \multirow{2}{*}{ Iga } & Mienoyume & $2.1=1.4$ & $86.3 \pm 3.2$ & $74.4 \pm 6.9$ & $20.6 \pm 0.6$ & $635 \pm 25$ & $399.3=13.0$ & $23.4 \pm 0.1$ & $6.9 \pm 0.0$ & $91.5 \pm 0.8$ & $5.06 \pm 0.08$ & $2.66 \pm 0.02$ & $1.90=0.04$ \\
\hline & $t$-test & & & & & & & $p=0.06$ & $*$ & $p=0.06$ & & $*$ & \\
\hline
\end{tabular}

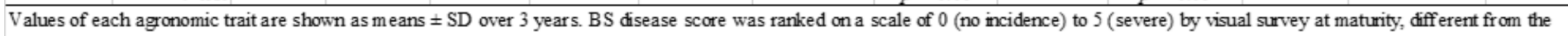

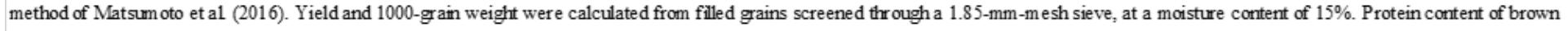

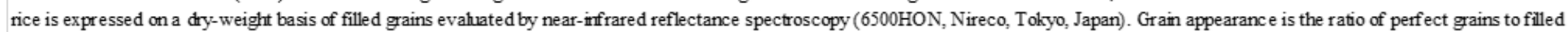

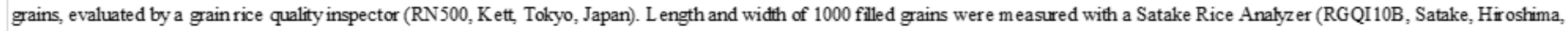
Japan). *Significant at $5 \%, p<0.10$ is indicated

Table 3 Agronomic traits of bsr 1-NIL and Mienoyume in the BS test field in 2020

\begin{tabular}{|c|c|c|c|c|c|c|c|c|c|c|c|c|}
\hline \multirow{4}{*}{$\begin{array}{l}\text { Line or } \\
\text { variety }\end{array}$} & \multirow{3}{*}{$\begin{array}{c}\text { BS } \\
\text { dise ase } \\
\text { score }\end{array}$} & \multicolumn{3}{|c|}{ At the panicle formation stage } & \multicolumn{6}{|c|}{ Y ield and yield components } & \multirow{3}{*}{$\begin{array}{c}\text { Protein } \\
\text { content of } \\
\text { brown rice }\end{array}$} & \multirow{3}{*}{$\begin{array}{c}\text { Grain } \\
\text { appearance }\end{array}$} \\
\hline & & \multirow{2}{*}{$\begin{array}{l}\text { Plant } \\
\text { height }\end{array}$} & \multirow{2}{*}{$\begin{array}{l}\text { Stem } \\
\text { number }\end{array}$} & \multirow{2}{*}{$\begin{array}{l}\text { SPAD } \\
\text { value }\end{array}$} & \multicolumn{2}{|c|}{ Brown rice yield } & \multirow{2}{*}{$\begin{array}{l}\text { Panicle } \\
\text { number }\end{array}$} & \multirow{2}{*}{$\begin{array}{l}\text { Spikelet number } \\
\text { per panicle }\end{array}$} & \multirow{2}{*}{$\begin{array}{l}\text { Percentage of } \\
\text { filled spikelets }\end{array}$} & \multirow{2}{*}{$\begin{array}{c}1000 \text {-grain } \\
\text { weight }\end{array}$} & & \\
\hline & & & & & Yield & $\begin{array}{c}\text { Yield } \\
\text { comparision }\end{array}$ & & & & & & \\
\hline & $(0-9)$ & $(\mathrm{cm})$ & $\left(\mathrm{m}^{-2}\right)$ & & $\left(\mathrm{g} \mathrm{m}^{-2}\right)$ & $(\%)$ & $\left(\mathrm{m}^{-2}\right)$ & (panicle) & $(\%)$ & (g) & $(\%)$ & $(\%)$ \\
\hline bsr 1 -NIL & $4.0 \pm 0.0$ & $79.9 \pm 2.1$ & $565.9 \pm 41.1$ & $36.1 \pm 2.5$ & $474 \pm 42$ & 128.8 & $352.7 \pm 2.6$ & $87.3 \pm 3.2$ & $67.1 \pm 6.4$ & $22.7 \pm 0.2$ & $7.7 \pm 0.1$ & $91.1=1.4$ \\
\hline Mienoyume & $7.0 \pm 0.0$ & $81.8=1.1$ & $600.7 \pm 60.0$ & $36.8=0.8$ & $368=18$ & 100.0 & $383.6 \pm 18.5$ & $82.1=10.2$ & $54.8 \pm 3.1$ & $22.3 \pm 0.0$ & $9.0=0.6$ & $87.8=1.7$ \\
\hline$t$-test & **** & & & & $*$ & & & & $*$ & $p=0.06$ & $*$ & $p=0.06$ \\
\hline
\end{tabular}

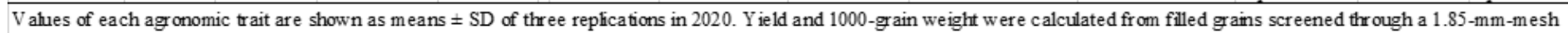

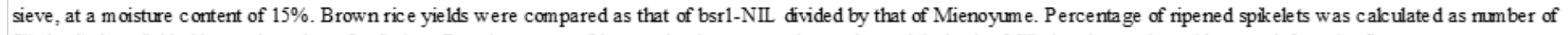

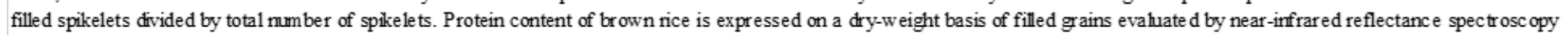

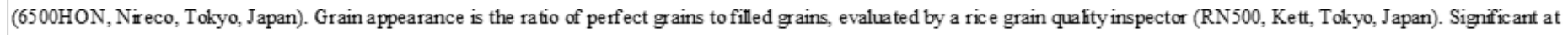
$* 5 \%, * * * 0.1 \%, p<0.10$ is indic ate $\mathrm{d}$

\section{Resistance of bsr1-NIL to other isolates of BS fungus}

At the seedling stage, the disease score of bsr1-NIL was significantly lower than that of Mienoyume following artificial inoculation of B. oryzae T. AOKI AR0126 and F-1 (Table 4). Thus, bsr1-NIL showed resistance to multiple isolates of BS fungus. 
Table 4 Disease resistance reactions to two BS isolates under artificial inoculation in the greenhouse

\begin{tabular}{|c|c|c|}
\hline \multirow{2}{*}{ Line and variety } & \multicolumn{2}{|c|}{ Disease score } \\
\hline & T. AOKI AR0126 & F-1 \\
\hline bsrl-NIL & $2.7 \pm 0.6 \mathrm{~b}$ & $2.0 \pm 0.0 \mathrm{~b}$ \\
\hline Mienoyume & $4.3 \pm 0.6 \mathrm{c}$ & $5.0 \pm 0.0 \mathrm{c}$ \\
\hline Tadukan & $1.0 \pm 0.0 \mathrm{a}$ & $1.0 \pm 0.0 \mathrm{a}$ \\
\hline ANOVA & $* * *$ & $* * *$ \\
\hline \multicolumn{3}{|c|}{$\begin{array}{l}\text { Disease scores are shown as means } \pm \text { SD. } * * * \text { Significant at } 0.1 \% \text {. Values followed by } \\
\text { the same letter within a column are not significantly different at } 5 \% \text { by Tukey-Kramer } \\
\text { test }\end{array}$} \\
\hline
\end{tabular}

\section{Discussion}

\section{Characteristics of BS-resistance QTL, qBSfR11}

Mienoyume is highly susceptible to BS and is more susceptible than Koshihikari (Matsumoto et al. 2017a). Here, we developed NILs with resistance to BS by using qBSfR11, derived from Tadukan, which had been identified as a major QTL responsible for resistance to BS (Sato et al. 2015). qBSfR11 had been previously confirmed to confer BS resistance in the Koshihikari genetic background (Sato et al. 2015). Here, it conferred resistance in the Mienoyume genetic background also (Table 3; Fig. 4). This result strongly indicates that $q B S f R 11$ is effective at conferring resistance to BS.

No resistance genes were found within the SSR marker interval RM1219 to RM27054 (Fig. 2a). The genotype of a resistant NIL in group-11 showed that $q B S f R 11$ was located around the 1.3-Mbp interval RM27073 to RM27159 (Fig. 2b). The candidate genomic region was narrowed from the donor parent R307-48-9. Annotation of the 'Nipponbare' sequence in RAP-DB shows 107 genes predicted within this interval (Sakai et al. 2013).

The distribution of $\mathrm{BS}$ disease scores in $153 \mathrm{BC}_{4} \mathrm{~F}_{2}$ individuals suggested that resistance to $\mathrm{BS}$ is controlled by a single recessive gene (Fig. 3). We named this gene bsr1 (brown spot resistance 1). Mwendo et al. (2017) reported that resistance to BS was controlled by one or two dominant genes, whereas Adair (1941) reported the involvement of several recessive genes. These present and previous studies show that there are different genes for BS resistance, with different modes of inheritance. Goel et al. (2006) suggested that pyramiding QTLs for BS resistance would be effective because the resistance in four lines of wild rice Oryza nivara showed quantitative inheritance. In future work, qBSfR11 should be an effective QTL for pyramiding to enhance BS resistance.

\section{Characteristics of bsr1-NIL}

By marker-assisted selection of foreground and background and BS resistance, bsr1-NIL was selected as a candidate for a practical variety with resistance to BS. 
Bipolaris oryzae is genetically diverse in Bangladesh (Kamal and Mia 2009), the Philippines (Burgos et al. 2013), India (Archana et al. 2014), and Iran (Ahmadpour et al. 2018). Inoculation of seedlings of 80 rice varieties with $107 \mathrm{~B}$. oryzae isolates collected from various regions in Japan revealed significant differences in pathogenicity; in some cases, the reaction was reversed depending on the combination of variety and isolate (Ohata 1989). Although race grouping of $B$. oryzae has not been reported so far, the existence of races is clear. Therefore, we tested whether bsr1-NIL was resistant to different $B$. oryzae strains. It showed resistance to B. oryzae T. AOKI AR0126 and F-1 (Table 4), as well as to B. oryzae Iga-2. This result suggests that BS-resistant NILs with $q B S f R 11$ will have resistance in different regions, at least in Japan.

The most important agronomic trait of the recurrent parent Mienoyume is its high yield. In Mie prefecture, the yield is about $600 \mathrm{~g} \mathrm{~m}^{-2}$ higher than that of Japan's most famous variety, Koshihikari (Kobayashi et al. 2018). bsr1-NIL had a higher yield than Mienoyume (Table 2). In addition, the results suggest that there may be useful new genes related to grain width and derived from Tadukan near bsr1; the higher yield of bsr1-NIL is likely to be due to the larger grain size. However, bsr1-NIL had the same grain length and grain length-width ratio as Mienoyume. bsr1-NIL has Mienoyume segments in all chromosomal regions except for the qBSfR11 region on Chr. 11. This shows that the homozygous Tadukan allele of bsr1-NIL in the qBSfR11 region increased grain width (Additional file 2: Fig. S1). Near this region, $\operatorname{tg} w 11$, associated with grain weight and grain width, was previously reported (Oh et al. 2011), but the tgw11 region did not overlap with the qBSfR11 region in which bsr1-NIL had the homozygous Tadukan allele. bsr1-NIL may have useful new genes related to grain width derived from Tadukan in the qBSfR11 region. Thus, Tadukan may be the source of not only BS resistance, but also of the large grain width.

\section{The effect of $q B S f R 11$ in improving rice yield and quality}

In the BS resistance test field, bsr7-NIL had 28.8\% higher yield than Mienoyume (Table 3). We inferred that the reason was the higher percentage of filled spikelets and larger 1000-grain weight. There were no significant differences in growth characteristics between bsr1-NIL and Mienoyume at the panicle formation stage, when BS was mild. BS became more severe after heading, and so is likely to affect ripening. The protein content of brown rice of bsr1-NIL was significantly lower than that Mienoyume. Vidhyasekharan and Ramadoss (1973) reported that severe infection reduced both yield ( 20\% to 40\%) and quality (i.e., increased protein content), as here. Dallagnol et al. (2014) reported that BS reduced yield by reducing grain number per panicle, 1000-grain weight, and the percentage of filled grains. Aluko (1975) reported that severe infection reduced grain number per panicle and individual grain weight, resulting in a yield loss of $30 \%$ to $43 \%$, compared with only $12 \%$ under moderate infection. The BS pathogen attacks the rice plant from seedling to milk stage (Sunder et al. 2014). The degree of yield loss and contributing factors are thought to vary depending on the degree and timing of BS infection. If BS is serious at an earlier stage than here, there is a high possibility that BS will affect not only ripening, but also yield components such as panicle number, and damage will be greater. Because BS resistance QTL, $q B S 11$, which detected in the same region as $q B S f R 11$ (Sato et al. 2015), has resistance to BS at the seedling stage of rice (Sato et al. 2008), bsr7-NIL is expected to have resistance even if BS occurs at an earlier 
stage than here. On the other hand, bsr1-NIL had a lower yield in the BS resistance test field than in the yield-trial field, although its yield decrease was smaller than that of Mienoyume (Tables 2,3). As the resistance type of bsr1-NIL with qBSfR11 is not true resistance but field resistance, pyramiding of QTLs is required for further enhancement of BS resistance.

\section{First practical breeding variety with resistance to BS}

We submitted bsr1-NIL for variety registration with the Ministry of Agriculture, Forestry and Fisheries in

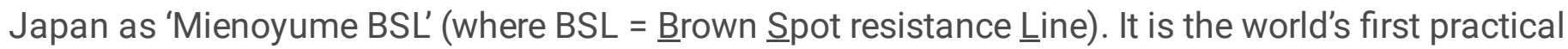
breeding variety with resistance to BS.

\section{Conclusion}

We developed a candidate NIL as a practical variety with resistance to BS. Characteristics of the BS resistance QTL, $q B S f R 11$, were revealed. The resistance of the $q B S f R 11$ region is controlled by a recessive gene within a 1.3-Mbp region on Chr. 11. We named the gene bsr1 (brown spot resistance 1). bsr1-NIL, which incorporates $q B S f R 11$ in the susceptible variety Mienoyume, had a significantly lower BS disease score and $28.8 \%$ higher yield in the presence of severe BS than Mienoyume. It also had significantly higher yield with larger grain width than Mienoyume and similar other agronomic traits in the presence of mild BS when there was no significant difference in BS disease score between the two. It showed resistance to multiple isolates of BS fungus. We submitted it for variety registration as 'Mienoyume BSL'. It is the world's first practical variety with resistance to BS. However, although it has practical BS resistance, it did not show true resistance, and so its yield was lower in the presence of severe BS than in the presence of mild BS. It will be necessary to search for new resistance QTLs or genes and pyramid them in order to enhance BS resistance.

\section{Abbreviations}

BS: Brown spot; QTL: Quantitative trait locus; NIL: Near-isogenic line; MAS: Marker-assisted selection; SSR: Simple sequence repeat; SNP: Single-nucleotide polymorphism; CTAB: Cetyl trimethylammonium bromide; PCR: Polymerase chain reaction

\section{Declarations}

\section{Acknowledgements}

We thank Mr. Y Nakayama and field managers of Mie Prefecture Agricultural Research Institute, Mr. M Kosaka, Ms. M Kato, Mr. H Najime, Mr. Y Miyamoto, Mr. Y Nakabayashi, Mr. N Moriguchi and Mr. S Okumura for their support during our study.

\section{Author's Contributions}


$\mathrm{KM}$ designed the research and wrote the manuscript; $\mathrm{KM}$ and $\mathrm{YO}$ mainly performed the experiments and analyzed data; TY, TO, YH performed phenotypic examinations of NILS; SS selected individuals with MAS for foreground; RM and HS selected individuals and lines with MAS for foreground and background, and oversaw and improved manuscript. The authors read and approved the final manuscript.

\section{Funding}

This work was supported by grants from the Ministry of Agriculture, Forestry and Fisheries of Japan (Project for "Development of mitigation and adaptation techniques to global warming in the sectors of agriculture, forestry, and fisheries", Rice \#2006; Project for "Climate Change”, Rice BGW-1201).

\section{Availability of Data and Materials}

The all datasets supporting the conclusions of this article are included in the article and supplementary files.

\section{Ethics Approval and Consent to Participate}

Not applicable.

\section{Consent for Publication}

Not applicable.

\section{Competing Interests}

The authors declare that they have no competing interests.

\section{References}

1. Adair CR (1941) Inheritance in rice of reaction to Helminthosporium oryzae and Cercospora oryzae. Technical Bulletin, United States Department of Agriculture, Washington, D.C. No.772:1-18

2. Aluko MO (1975) Crop losses caused by the brown leaf spot disease of rice in Nigeria. Plant Disease Reporter 59:609-613

3. Ahmadpour A, Castell-Miller C, Javan-Nikkhah M, Naghavi MR., Dehkaei FP, Leng Y, Puri KD, Zhong S (2018) Population structure, genetic diversity, and sexual state of the rice brown spot pathogen Bipolaris oryzae from three Asian countries. Plant Pathology 67:181-192

4. Archana B, Kini KR, Prakash HS (2014) Genetic diversity and population structure among isolates of the brown spot fungus, Bipolaris oryzae, as revealed by inter-simple sequence repeats (ISSR). Afr J Biotechnol 13:2-38

5. Barnwal MK, Kotasthane A, Magculia N, Mukherjee PK, Savary S, Sharma AK, Singh HB, Singh US, Sparks AH, Variar M, Zaidi N (2013) A review on crop losses, epidemiology and disease management 
of rice brown spot to identify research priorities and knowledge gaps. Eur J Plant Pathol 136(3):443457

6. Burgos MRG, Katimbang MLB, Paz MD, Beligan GA, Goodwin PH, Ona IP, Mauleon RP, Ardales EY, Cruz CV (2013) Genotypic variability and aggressiveness of Bipolaris oryzae in the Philippines. Eur J Plant Pathol 137(2):415-429

7. Chakrabarti NK (2001) Epidemiology and disease management of brown spot of rice in India. In: Major Fungal Diseases of Rice Recent Advances. Kluwer Academic Publishers. Printed in the Netherlands. pp 293-306

8. Dallagnol LJ, Rodrigues FA, Mielli MVB, Ma JF (2014) Rice grain resistance to brown spot and yield are increased by silicon. Trop Plant Pathol 39(1):56-63

9. Datnoff LE, Raid RN, Snyder GH, Jones DB (1991) Effect of calcium silicate on blast and brown spot intensities and yields of rice. Plant Dis 75(7):729-732

10. Eruotor PG (1986) Varietal reaction of rice to isolates of Cochliobolus miyabeanus. Indian Phytopath 39:62-64

11. Goel RK, Bala R, Singh K (2006) Genetic characterization of resistance to brown leaf spot caused by Drechslera oryzae in some wild rice (Oryza sativa) lines. Indian Journal of Agricultural Sciences 76(11):705-707

12. Ishizaki K, Hoshi T, Abe S, Sasaki Y, Kobayashi K, Kasaneyama H, Matsui T, Azuma S (2005) Breeding of blast resistant isogenic lines in rice variety 'Koshihikari' and evaluation of their characters. Breed Sci 55:371-377

13. JPPA (1975-2019) JPP-NET. http://web1.jppn.ne.jp. Accessed 22 Nov 2020.

14. JPPA (2019) Epidemic and controlling areas in 2018. In: Japan Plant Protection Association (ed) Catalogue of agricultural chemicals, Tokyo, pp 600-603

15. Kamal MM, Mia MAT (2009). Diversity and pathogenicity of the rice brown spot pathogen, Bipolaris oryzae (Breda de Haan) shoem. in Bangladesh assessed by genetic fingerprint analysis. Bangladesh J Bot 38:195-200

16. Katara JL, Sonah H, Deshmukh RK, Chaurasia R, Kotasthane AS (2010) Molecular analysis of QTLs associated with resistance to brown spot in rice (Oryza sativa). Indian J Genet $\mathrm{PI} \mathrm{Br}$ 70(1):17-21

17. Kobayashi A, Hori K, Yamamoto T, Yano M (2018) Koshihikari: a premium short-grain rice cultivar its expansion and breeding in Japan. Rice 11:15

18. Matsumoto K, Sato H, Ota C, Seta S, Yamakawa T, Suazuki H, Nakayama Y (2016) A new method for evaluating field resistance to brown spot in rice. Breed Res 18:103-111 (in Japanese with English summary)

19. Matsumoto K, Seta S, Ota C, Ohno T, Ota Y, Nakayama Y, Yamakawa T, Sato H (2017a) Search for genetic resources resistant to brown spot in NIAS core collections of Japanese rice landraces and world rice. Breed Res 19:155-163 (in Japanese) 
20. Matsumoto K, Ota Y, Seta S, Nakayama Y, Ohno T, Mizobuchi R, Sato H (2017b) Identification of QTLs for rice brown spot resistance in backcross inbred lines derived from a cross between Koshihikari and $\mathrm{CH} 45$. Breed Sci 67:540-543

21. McCouch SR, Teytelman L, Xu Y, Lobos KB, Clare K, Walton M, Fu B, Maghirang R, Li Z, Xing Y, Zhang Q, Kono I, Yano M, Fjellstrom R, DeClerck G, Schneider D, Cartinhour S, Ware D, Stein L (2002) Development and mapping of 2,240 new SSR markers for rice (Oryza sativa L.). DNA Res 9:199-207

22. Misra AK (1985) Effect of intercepting populations of resistant cultivars on reducing brown spot disease build up in a susceptible rice cultivar. Indian Phytopath 38: 66-69

23. Mizobuchi R, Fukuoka S, Tsushima S, Yano M, Sato H (2016) QTLs for resistance to major rice diseases exacerbated by global warming: brown spot, bacterial seedling rot, and bacterial grain rot. Rice 9:23

24. Murray MG, Thompson WF (1980) Rapid isolation of highmolecular-weight plant DNA. Nucleic Acids Res 8:4321-4325

25. Mwendo MM, Ssemakula MO, Mwale SE, Lamo J, Gibson P, Edema R (2017) Inheritance of resistance to brown spot disease in upland rice in Uganda. J Plant Breed Crop Sci 9(4):37-44

26. Nagasaki H, Ebana K, Shibaya T, Yonemaru J, Yano M (2010) Core single-nucleotide polymorphisms -a tool for genetic analysis of the Japanese rice population. Breed Sci 60:648-655

27. Oh JM, Balkunde S, Yang P, Yoon DB, Ahn SN (2011) Fine mapping of grain weight QTL, tgw11 using near isogenic lines from a cross between Oryza sativa and grandiglumis. Genes Genome 33(3):259265

28. Ohata K (1989) Brown spot disease. In: Rice Diseases. Zenkoku Nouson Kyouiku Kyoukai, Printed in Japan, pp 357-374 (in Japanese)

29. Ohata K, Kubo $C$ (1974) Studies on the mechanism of disease resistance of rice varieties to Cochliobolus miyabeanus. Bull Shikoku Agric Exp Stn 28:17-57 (in Japanese)

30. Ou SH (1985) Rice diseases, 2nd edn. Commonwealth Micological Institute, Kew, UK, pp 1-380

31. Sakai H, Lee SS, Tanaka T, Numa H, Kim J, Kawahara Y, Wakimoto H, Yang CC, Iwamoto M, Abe T, Yamada Y, Muto A, Inokuchi H, Ikemura T, Matsumoto T, Sasaki T, Itoh T (2013) Rice Annotation Project Database (RAP-DB): an integrative and interactive database for rice genomics. Plant Cell Physiol 54:e6

32. Sato H, Ando I, Hirabayashi H, Takeuchi Y, Arase S, Kihara J, Kato H, Imbe T, Nemoto H (2008) QTL analysis of brown spot resistance in rice (Oryza sativa). Breed Sci 58(1):93-96

33. Sato H, Matsumoto K, Ota C, Yamakawa T, Kihara J, Mizobuchi R (2015) Confirming a major QTL and finding additional loci responsible for field resistance to brown spot (Bipolaris oryzae) in rice. Breed Sci 65(2):170-175

34. Sunder S, Singh R, Agarwal R (2014) Brown spot of rice: an overview. Indian Phytopath 67(3):201215 
35. Vidhyasekharan P, Ramadoss N (1973) Quantitative and qualitative losses in paddy due to Helminthosporium epidemic. Indian Phytopath 16:479-84

36. Yamaguchi Y, Nakano K, Saito R (2007) An outbreak of rice brown spot at Niigata prefecture Kaetsu district in 2005 and 2006. The Association for Plant Protection of Hokuriku 59:4 (in Japanese)

37. Yamakawa T, Murakami T, Miyamoto K, Tachibana N, Hashidume F, Tatematsu N, Hattori H (2002) A newly developed paddy rice variety 'Mieoyume' with medium maturation and high grain quality. Bull Mie Agric Res 29:15-23 (in Japanese with English summary)

38. Yoshii H, Matsumoto M (1951) Studies on the resistance to Helminthosporiose of the rice varieties introduced to Japan (1). Bull Matsuyama Agric College 6:25-60 (in Japanese)

\section{Figures}




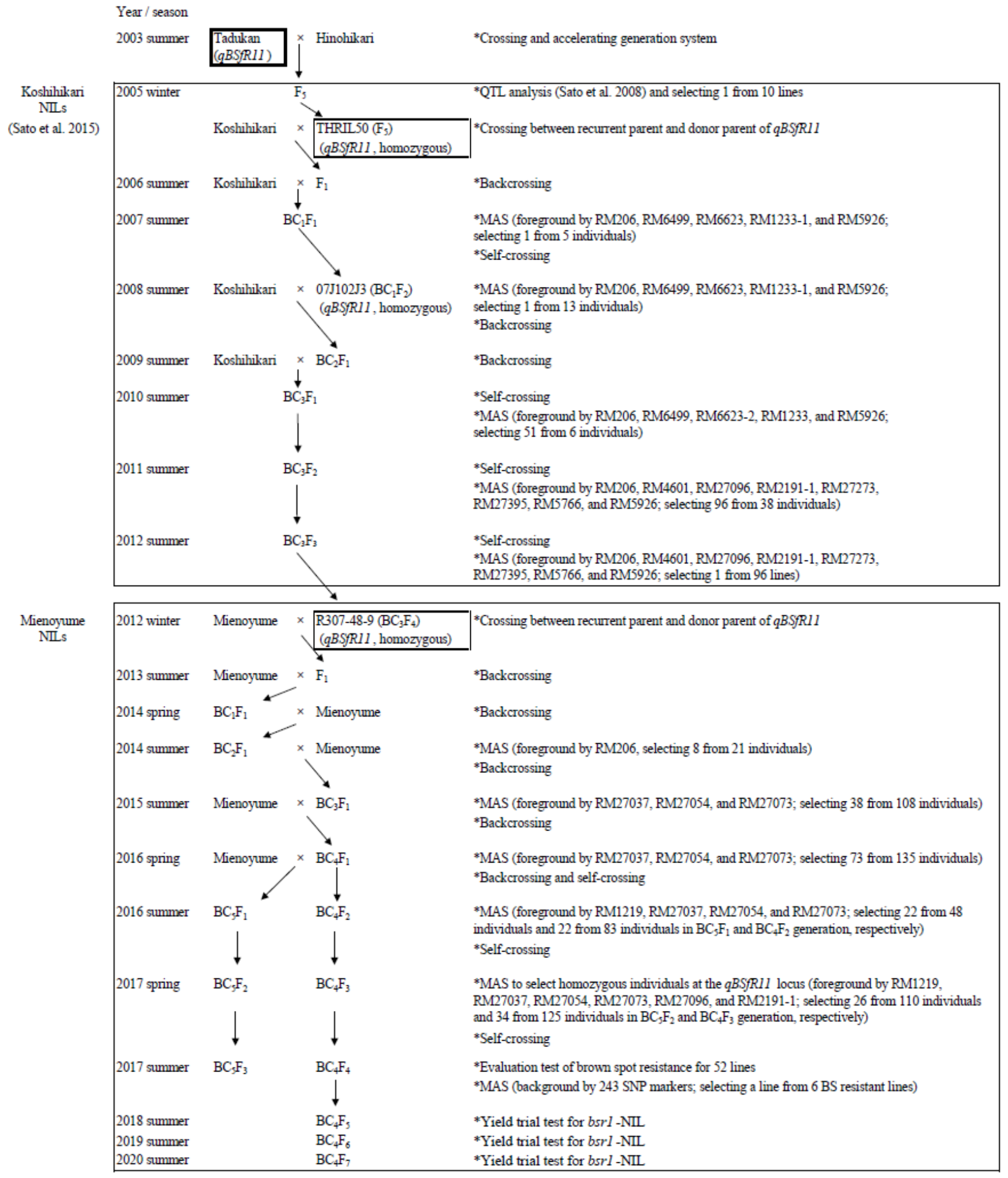

\section{Figure 1}

Breeding scheme for development of Mienoyume NILs 


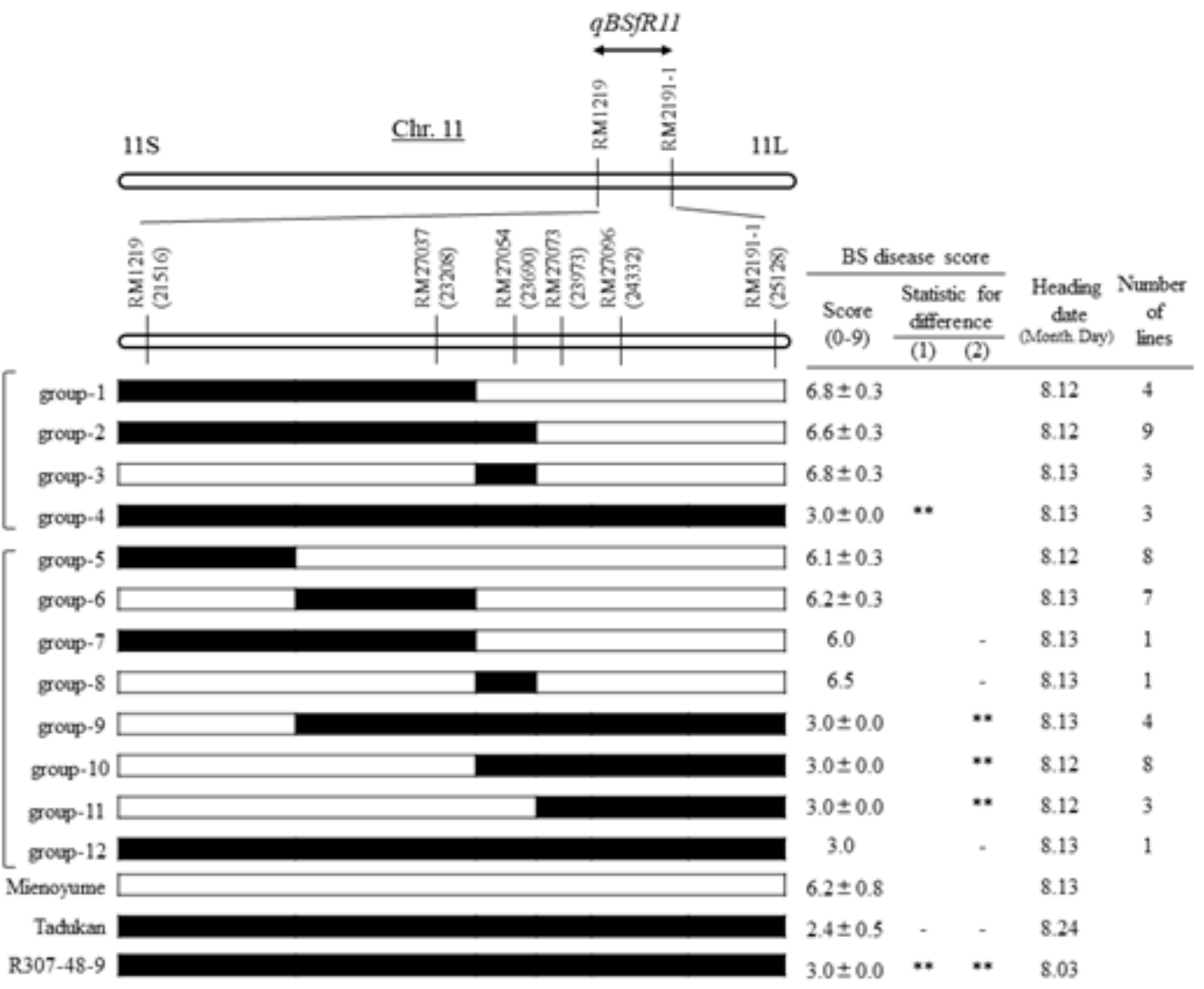

$\mathrm{b}$

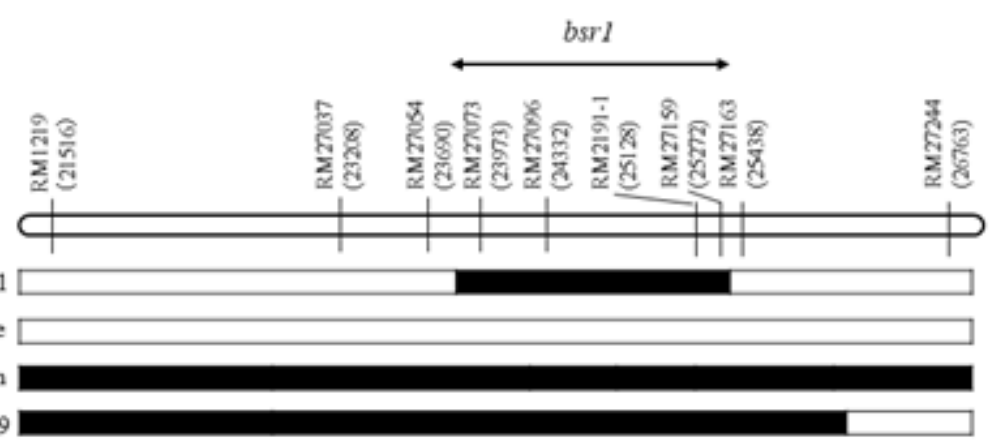

Figure 2

Graphical genotypes in the qBSfR11 region on Chr. 11 by SSR analyses in (a) 2016 and (b) 2018. Homozygous for Mienoyume; $\square$ homozygous for Tadukan. Numbers in parentheses beside SSR markers indicate their physical map positions (kbp) on Chr. 11 in IRGSP v. 1.0. a 52 NILs in BC5F3 or BC4F4 generation with their BS disease scores (means \pm SD) and heading dates in 2017. **Significant difference from Mienoyume at 1\% in (1) BC5F3 and (2) BC4F4 generations (except in groups with one line) by Dunnett's test. There was no significant difference in heading dates between NILs (both generations) and Mienoyume at $5 \%$ by Dunnett's test. b NIL of group-11 


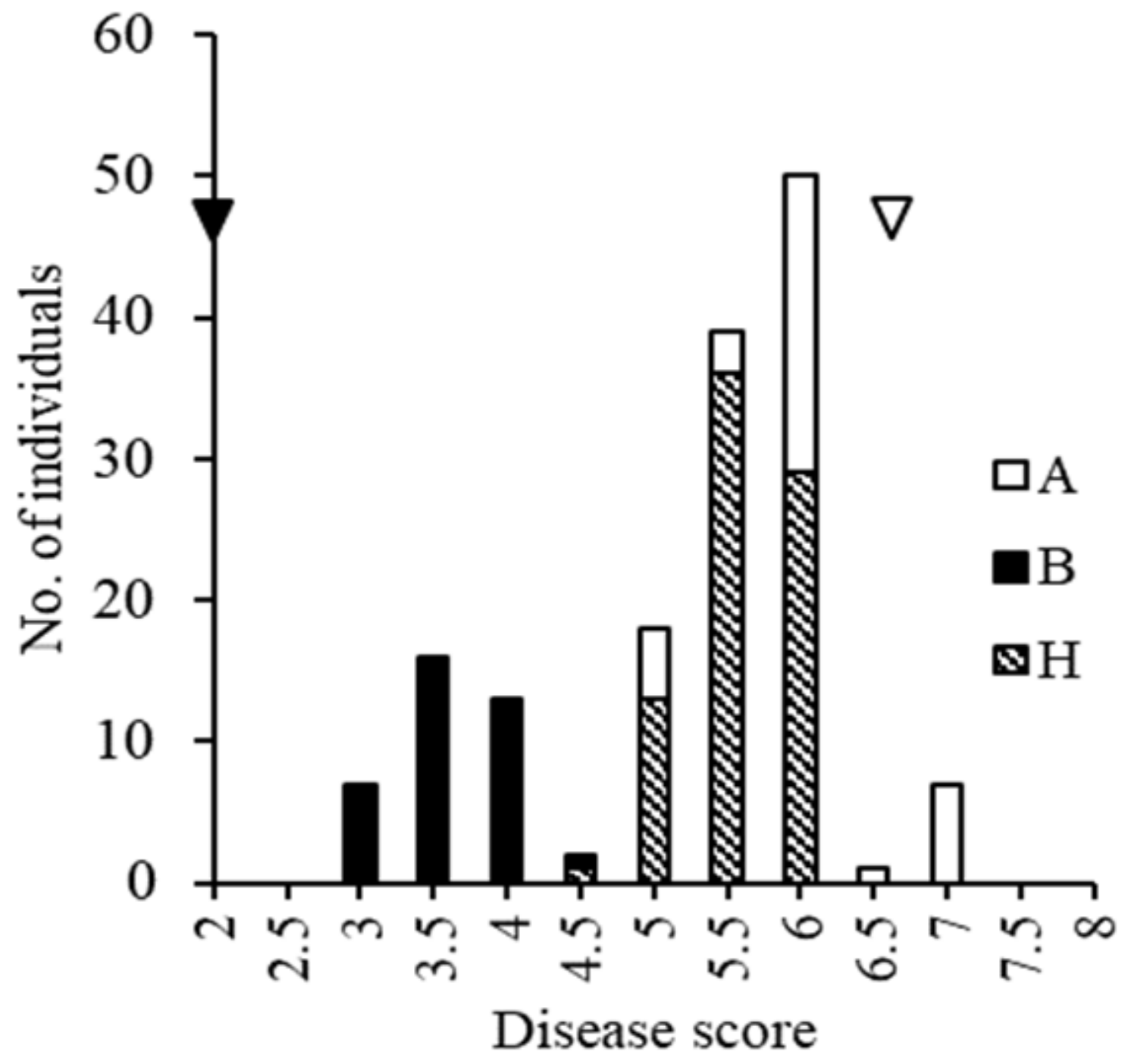

Figure 3

Frequency distribution of BS disease scores in 153 BC4F2 individuals derived from one BC4F1 individual and based on the genotypes of a SSR marker RM27073. Bars: $\square$ homozygous for Mienoyume allele (A),

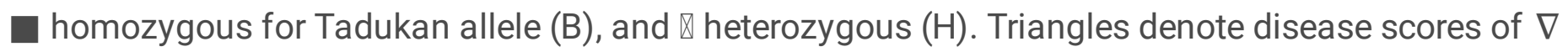
Mienoyume (6.7: susceptible) and $\boldsymbol{\nabla}$ Tadukan (2.0: resistant) 


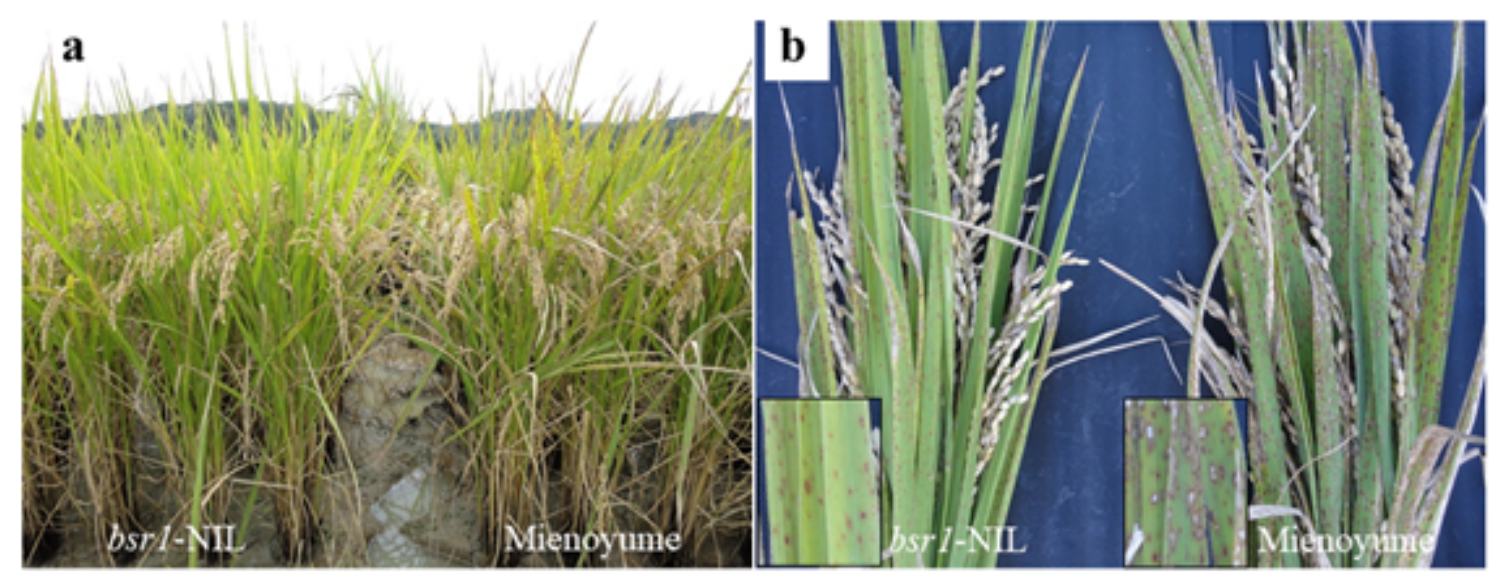

c

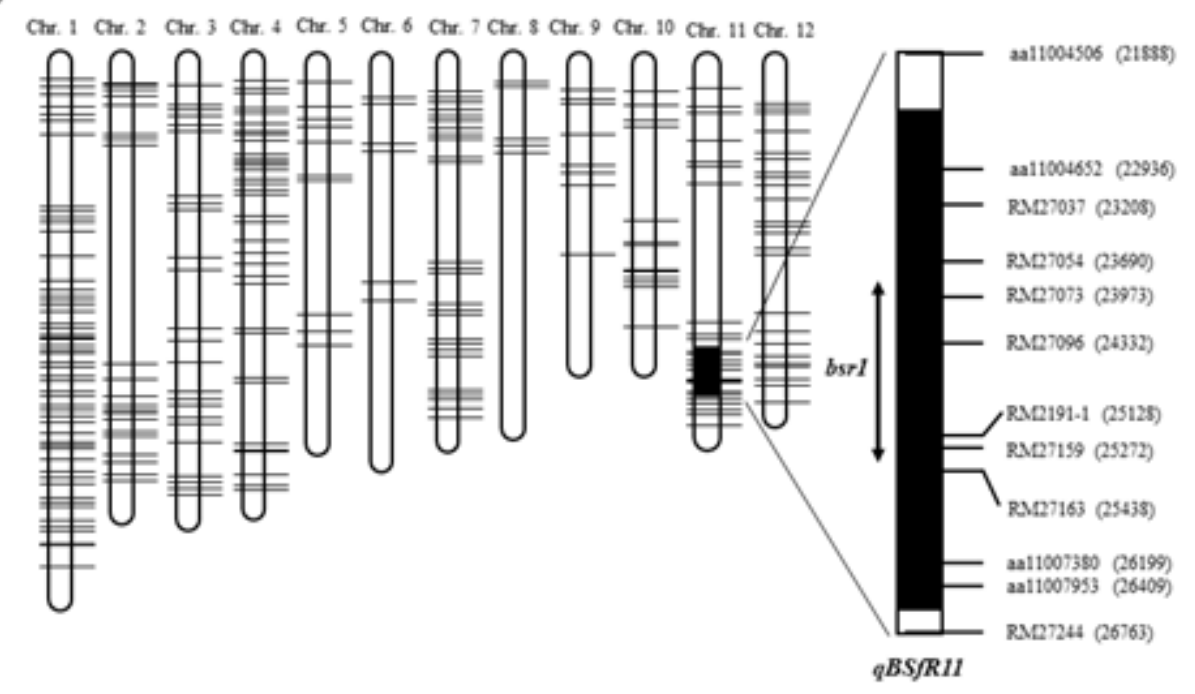

Figure 4

Phenotype and genotype of bsr1-NIL. a Test plot in the BS test field. b BS lesions appeared on each plant. c Graphical genotype. $\square$ Homozygous for Mienoyume; $\square$ homozygous for R307-48-9. Numbers in parentheses beside markers indicate their physical map positions (kbp) on Chr. 11 in IRGSP v. 1.0. Detailed information of SNP markers used for this mapping is shown in Additional file 1: Table S1

\section{Supplementary Files}

This is a list of supplementary files associated with this preprint. Click to download.

- TableS1.xIsx

- Fig.S1.pptx 